\title{
A Novel Approach to Stabilize Foam Using Fluorinated Surfactants
}

\author{
Muhammad Shahzad Kamal 1 \\ Center for Integrative Petroleum Research, King Fahd University of Petroleum \& Minerals, Dhahran 31261, \\ Saudi Arabia; shahzadmalik@kfupm.edu.sa; Tel.: +966-13-860-8513
}

Received: 9 February 2019; Accepted: 22 March 2019; Published: 26 March 2019

\begin{abstract}
Selection of surfactants for enhanced oil recovery and other upstream applications is a challenging task. For enhanced oil recovery applications, a surfactant should be thermally stable, compatible with reservoir brine, and have lower adsorption on reservoir rock, have high foamability and foam stability, and should be economically viable. Foam improves the oil recovery by increasing the viscosity of the displacing fluid and by reducing the capillary forces due to a reduction in interfacial tension. In this work, foamability and foam stability of two different surfactants were evaluated using a dynamic foam analyzer. These surfactants were fluorinated zwitterionic, and hydrocarbon zwitterionic surfactants. The effect of various parameters such as surfactant type and structure, temperature, salinity, and type of injected gas was investigated on foamability and foam stability. The foamability was assessed using the volume of foam produced by injecting a constant volume of gas and foam stability was determined by half-life time. The maximum foam generation was obtained using hydrocarbon zwitterionic surfactant. However, the foam generated using fluorinated zwitterionic surfactant was more stable. A mixture of zwitterionic fluorinated and hydrocarbon fluorinated surfactant showed better foam generation and foam stability. The foam generated using $\mathrm{CO}_{2}$ has less stability compared to the foam generated using air injection. Presence of salts increases the foam stability and foam generation. At high temperature, the foamability of the surfactants increased. However, the foam stability was reduced at high temperature for all type of surfactants. This study helps in optimizing the surfactant formulations consisting of a fluorinated and hydrocarbon zwitterionic surfactant for foam injections.
\end{abstract}

Keywords: foam stability; zwitterionic surfactant; fluorinated surfactant; $\mathrm{CO}_{2}$ recovery

\section{Introduction}

Foam is a thermodynamically unstable two-phase mixture where inner phase consists of gas and outer phase is a liquid. Gas is made discontinuous in foam by a thin film which has been referred to in the literature with different names such as foam film, soap film, liquid lamellae, and free-standing liquid film [1]. The foam film is usually stabilized using different surfactants and recently nanoparticles have also been used for this purpose either alone or with surfactants. Foam has different applications in oil and gas industry such as in drilling, hydraulic fracturing, and in enhanced oil recovery (EOR) [2-6]. $\mathrm{CO}_{2}$ flooding is one of the most commonly used EOR method that involves the injection of compressed $\mathrm{CO}_{2}$ [7-9]. In EOR methods that employ low viscous fluids as displacing slugs such as $\mathrm{CO}_{2}$ flooding, the foam is applied to improve the sweep efficiency by controlling the gas mobility. Foam usually control the gas mobility by overcoming several drawbacks such as viscous fingering (due to viscosity contrast), gravity override (density contrast), and gas channeling (due to the heterogeneity of the reservoirs) [10]. The mechanism of oil recovery by foam differs from that of surfactant flooding owing to the presence of the gas phase. Besides foaming, the surfactant lowers the interfacial tension between water and hydrocarbons. Therefore, foam improve the oil recovery by increasing the viscosity 
of displacing fluid and by reducing the capillary forces due to reducing interfacial tension [11]. The extensive application of foam in upstream applications is restricted owing to poor foam stability and inadequate understanding of the mechanism.

Foamability and foam stability are two important parameters to characterize the foam [12]. Foamability is directly related to the capacity to produce foam while the half-life of the foam is used to characterize the foam stability. Both foamability and foam stability are related to the structure of the surfactants, concentration of the surfactant, salinity, temperature, type of the gas, adsorption kinetics, surface forces and gas diffusion through foam films. The foamability of the surfactant is closely related to the interfacial tension. The lower interfacial tension decreases the required external forces to generate the finely textured foam [13].

The foam stability of any surfactant is determined by the interaction of different factors which include both bulk phase and interface properties [13]. For bulk phase, gravity drainage and gas diffusion cause the foam to destabilize. In porous media, additional factors such as capillary suction coalescence, capillary pressure, and interfacial elasticity determined the foam stability [14]. Interface properties such as interfacial tension and surface forces affect the foam stability. A surfactant having low surface tension and high surface viscoelasticity is generally considered a good foaming solution [15]. In freshly generated foam, the lamellae between two foam bubbles are thick, but the film starts thinning as liquid drains out of the lamella due to capillary pressure and gravity. The foam stability in presence of a different antifoaming agent such as alcohol and oil in the reservoir is one of the major challenges in the utilization of foam in EOR and fracturing [16].

Selection of surfactants for foaming application in EOR, $\mathrm{CO}_{2}$ sequestration, hydraulic fracturing, and other upstream applications is a challenging task [17-25]. A surfactant for foaming applications should be generally thermally stable, compatible with reservoir brine and other chemicals, have lower adsorption on reservoir rock, have high foamability and foam stability, and should be economically viable [26-30]. Nonionic surfactants usually precipitate above the cloud point temperature due to weaker hydrogen bonds at high temperature. The cloud point of nonionic surfactant further reduced by increasing the salinity [31,32]. Most of the cationic surfactants are also not stable at high temperature and high salinity conditions. Anionic surfactants such as sulfates are vulnerable to sulfur-oxygen bond hydrolysis [33].

Zwitterionic surfactants are highly soluble in a wide range of salinity and temperature conditions and are less investigated for foaming applications, especially for $\mathrm{CO}_{2}$ foam [34]. Zwitterionic surfactants also cause less irritation to eyes and skin compared to other classes of surfactants [35]. They are also compatible with other classes of surfactants and commonly used to enhance several properties. Most of the zwitterionic surfactants have less adsorption on carbonate rocks compared to the cationic and anionic surfactants that are extremely important for EOR applications [36].

In this work, the foamability and foam stability of two zwitterionic surfactants was evaluated under different conditions. One of the surfactants is fluorinated and the other surfactant is a hydrocarbon surfactant. These surfactants were selected as they showed good thermal stability and good salt tolerance in our previous work $[37,38]$. In addition, the surfactants have low adsorption on carbonate rock $(<1 \mathrm{mg} / \mathrm{g}$-rock) and good interfacial properties [37]. The objective of the work was to investigate the foaming properties of the surfactants in different conditions and to investigate the synergetic behavior of the hydrocarbon zwitterionic surfactant and fluorinated zwitterionic surfactant. This work focuses on bulk solution studies to understand the interactions between fluorinated and hydrocarbon zwitterionic surfactants. Understanding developed in this work will be utilized to investigate oil recovery potential in various rock using foam injection stabilized by fluorinated and hydrocarbon surfactant. 


\section{Materials and Methods}

\subsection{Materials}

Two surfactants (surfactant-A, surfactant-B) were used in this study. Surfactant-A was partially fluorinated betaine (Dupont, Paris, France), surfactant-B was a carboxybetaine-based zwitterionic surfactant (from Oil Chem Technol. Sugar Land, TX, USA). The structure of the surfactants is given in Figure 1. The seawater was synthesized by using different analytical grade salts such as sodium chloride, calcium chloride, sodium sulfate, sodium bicarbonate, and magnesium chloride. The total salinity of the synthetic seawater was 57,643 ppm and contains both monovalent and divalent cations. The composition of the brine is given in Table 1.<smiles>[R][N+](C)(C)CCCC(=O)[O-]</smiles>

Surfactant-B

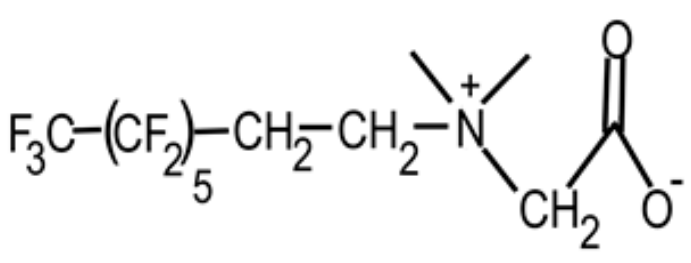

Surfactant-A

Figure 1. The structure of the surfactants used in this study.

Table 1. The composition of the synthetic seawater used in this study [39].

\begin{tabular}{cc}
\hline Ions & Concentration $(\mathbf{m g} / \mathbf{L})$ \\
\hline Sodium & 18,300 \\
Calcium & 650 \\
Magnesium & 2083 \\
Sulfate & 4290 \\
Chloride & 32,200 \\
Bicarbonate & 120 \\
TDS & 57,643 \\
\hline
\end{tabular}

\subsection{Foam Stability Test}

The foam analysis tests were performed with a DFA 100 system from Krüss (Hamburg, Germany). Surfactant solutions for the tests were prepared with deionized water (DW), seawater (SW), and formation water (FW). Filter papers of 12-15 $\mu \mathrm{m}$ were used in the experiments. They were put in a filter paper holder and the filter paper holder was put at the base of the measuring column holder. A sample volume of $50 \mathrm{~mL}$ was poured carefully with a syringe into a measuring column firmly clamped to the column holder.

Carbon dioxide and air were used as foam generators. The gases were flown through the filter paper at a rate of $0.2 \mathrm{~L} / \mathrm{min}$ for $50 \mathrm{~s}$. Tests with $\mathrm{CO}_{2}$ were conducted for surfactant solutions in DW, SW, and FW at $25^{\circ} \mathrm{C}$ and $80^{\circ} \mathrm{C}$. Tests with air were conducted on surfactant solutions in seawater at $25^{\circ} \mathrm{C}$. Temperature control at $80{ }^{\circ} \mathrm{C}$ was achieved with a water bath (Julabo, Allentown, PA, USA). All the tests were conducted for a maximum of $1.5 \mathrm{~h}$.

For tests conducted at $25^{\circ} \mathrm{C}$, a camera attached to the equipment to visualize bubble structure and distribution was placed at a height of $85 \mathrm{~cm}$ with the aid of the height scale of the equipment. This was to place the camera close to the foam-surfactant solution interface. Bubble structure was not recorded at $80^{\circ} \mathrm{C}$ as the measuring column used at this temperature was not designed for this purpose. The LED module and light detector module which are parallel to each other were placed $1 \mathrm{~mm}$ apart from the measuring columns used at both temperatures. The light detector module detects the amount of light generated by the LED module that passes through the foam and solution, thus measuring foam height and its subsequent decay. 


\section{Results and Discussion}

The discussion part is divided into three parts: the first part discusses the foaming properties using two different gases $\left(\mathrm{CO}_{2}\right.$, and air), second part discuss the effect of salinity, and third part deals the foaming behavior at high temperature.

The foaming behavior of the surfactant was evaluated using $\mathrm{CO}_{2}$ and air as a gas medium. Figure 2 shows the foamability of surfactant-A, surfactant-B and their mixtures using air and $\mathrm{CO}_{2}$ as a gas medium. The total concentration of all surfactants was $0.1 \%$. For all surfactants, the foam volume generated using air as a medium was much higher compared to the foam generated using $\mathrm{CO}_{2}$ as a gas medium. The difference between the foaming properties of air and $\mathrm{CO}_{2}$ is associated with their properties such as density, interfacial tension, and water solubility. Hydrocarbon zwitterionic surfactant (surfactant-B) showed higher foamability compared to the fluorinated zwitterionic surfactant (surfactant-A) both in $\mathrm{CO}_{2}$ and air case. However, the foam volume of surfactant-A exceeds the foam volume of surfactant- $\mathrm{B}$ in short time. For example, using $\mathrm{CO}_{2}$ as a gas medium, the foam volume of surfactant-A surpasses the foam volume of surfactant-B in 4 min. Similarly, in the case of air, the foam volume of surfactant-B becomes lower compared to the foam volume of surfactant-A in less than $15 \mathrm{~min}$. This shows that the hydrocarbon zwitterionic surfactants have higher foamability, however, the stability of the foam was less compared to the fluorinated surfactants. Synergetic action of hydrocarbon and fluorinated surfactant can improve the foamability and stability. For example, in both cases, the foam volume generated using a mixture of surfactant was higher compared to the surfactant-B. In addition, the foam volume for mixture was higher compared to surfactant-A for more than $25 \mathrm{~min}$ and $12 \mathrm{~min}$ for air and $\mathrm{CO}_{2}$ cases, respectively.

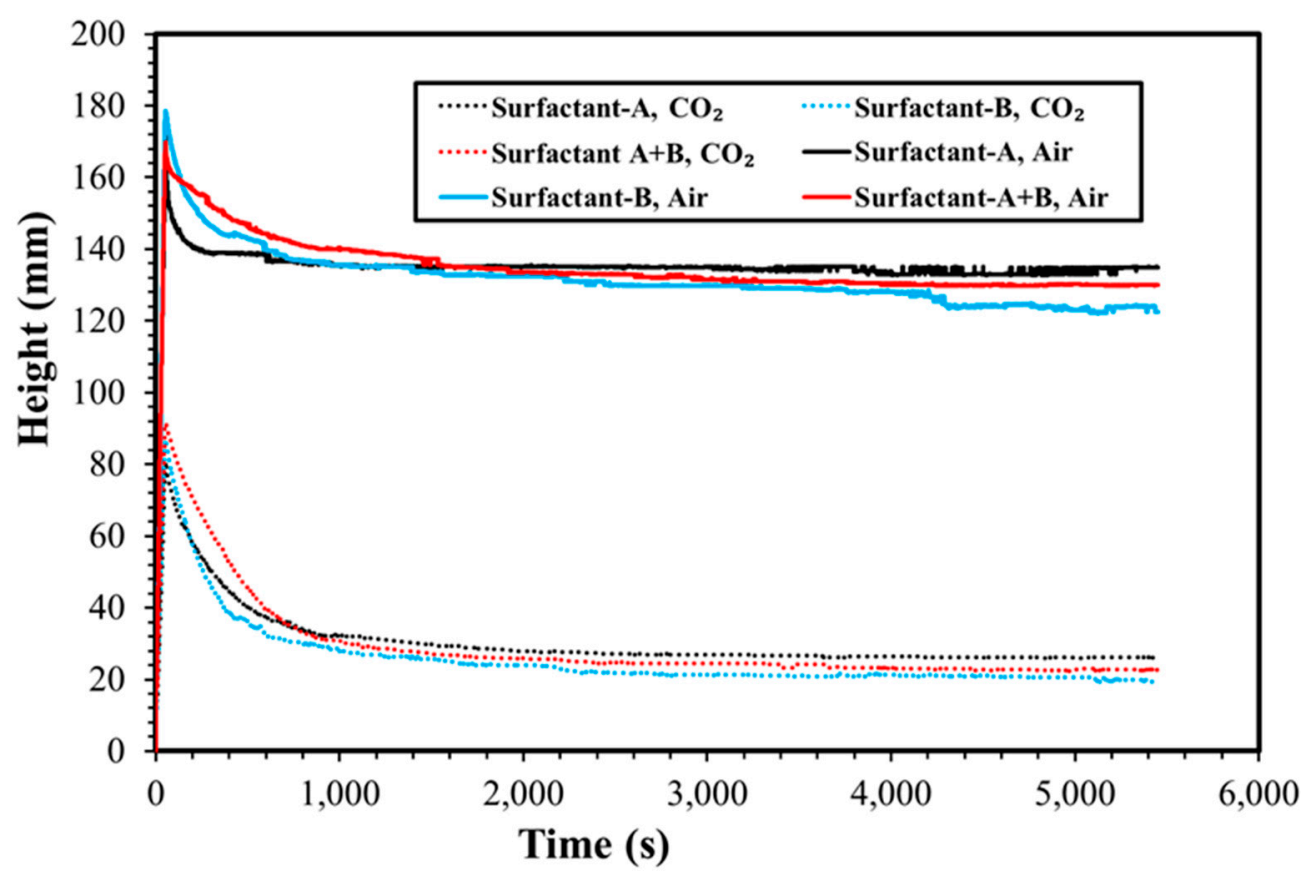

Figure 2. Foam height vs. time for different surfactant system using air and $\mathrm{CO}_{2}$ at $25^{\circ} \mathrm{C}$.

Foam stability of surfactants was determined using foam volume stability (FVS) parameter. FVS is defined as the percentage of foam volume remaining with respect to maximum foam volume after foaming has been stopped. The FVS was calculated by Equation (1) as given below:

$$
F V S(t)=\frac{V_{t(\text { foam })}}{V_{f(\text { foam })}} \times 100
$$


where $V$ is the volume, and subscript $t$ refers to the volume at a given time, and subscript $f$ refers to final condition (after foaming stopped or end of bubbling process). The foam half-life time ( $\mathrm{t}_{\mathrm{FVS5}} \%$ ) can be defined as the time at which FVS has been reduced to $50 \%$ of its initial value. Foam liquid stability (FLS) is another important parameter to characterize the foaming behavior that shows the ability of the foam to hold the liquid and measure the dryness of the foam. The drainage half-life time $\left(t_{\mathrm{FLS50}} \%\right)$ is defined as the time at which FLS has reduced to $50 \%$ of its initial value.

$$
F L S(t)=\frac{V_{i(l i q)}-V_{t(l i q)}}{V_{i(l i q)}-V_{f(l i q)}} \times 100
$$

Here $i$ refers to initial condition before gas was bubbled through the test solution. The FVS of the surfactants using air injection are shown in Figure 3. Table 2 shows the $t_{\mathrm{FVS} 50 \%}$ values of different foaming systems at varying conditions. In this study, the half-life time of the foam generated using air was more than $1.5 \mathrm{~h}$. Till the end of the experiment, the foam volume stability was more than $50 \%$ i.e., half-life time did not reach. However, for a $\mathrm{CO}_{2}$ system, half-life time was much lower compared to the foam generated using air. Wang et al. compared the foam stability of the sodium dodecyl surfactant for $\mathrm{CO}_{2}$ and $\mathrm{N}_{2}$ gas [40]. They observed that the half-life time of the $\mathrm{N}_{2}$ foam was up to five times higher compared to the $\mathrm{CO}_{2}$ foam. The stability of the foam is mainly related to the mass transfer rate and film permeability. The mass transfer rate of gas through a foam film is characterized by film permeability defined by Princen and Mason's Equation (3) [41]:

$$
K=\frac{D H}{h_{w}+2 D / k_{m l}}
$$

where $D$ is the diffusion coefficient, $h_{w}$ is the thickness of the liquid film, $k_{m l}$ is the permeability of the surfactant monolayer to gas, and $H$ is Henry's law constant. The value of $K$ for $\mathrm{CO}_{2}$ is manifold higher compared to the value of $K$ for air [41-43]. For $\mathrm{CO}_{2}$ foam, the higher $K$ values mean a higher gas diffusion rate that is the main reason for less foam stability.

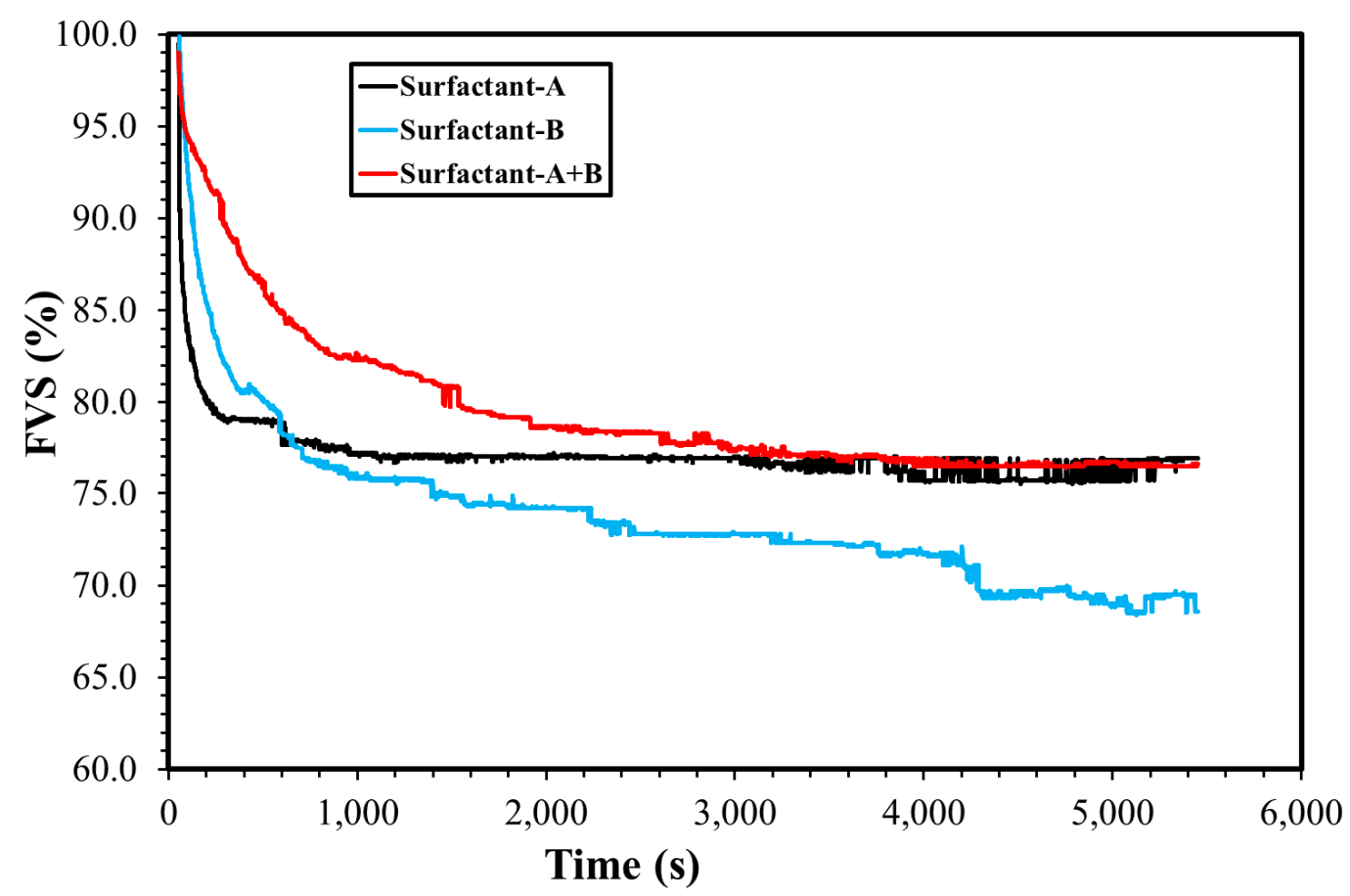

Figure 3. FVS of surfactants using seawater and air as a gas medium at $25^{\circ} \mathrm{C}$. 
Table 2. Half-life time of different foam systems.

\begin{tabular}{cccccc}
\hline Surfactant & Gas & Water & $\mathbf{T}\left({ }^{\circ} \mathbf{C}\right)$ & $\mathbf{t}_{\text {FVS50\% }}(\mathbf{s})$ & $\mathbf{t}_{\mathbf{F L S 5 0} \%}$ \\
\hline A & Air & SW & 25 & $>5400$ & 60 \\
B & Air & SW & 25 & $>5400$ & 135 \\
A + B & Air & SW & 25 & $>5400$ & 286 \\
A & $\mathrm{CO}_{2}$ & SW & 25 & 485 & 84 \\
B & $\mathrm{CO}_{2}$ & SW & 25 & 332 & 114 \\
A + B & $\mathrm{CO}_{2}$ & SW & 25 & 495 & 246 \\
A & $\mathrm{CO}_{2}$ & DW & 25 & 215 & 67 \\
B & $\mathrm{CO}_{2}$ & DW & 25 & 158 & 73 \\
A + B & $\mathrm{CO}_{2}$ & DW & 25 & 269 & 98 \\
A & $\mathrm{CO}_{2}$ & SW & 80 & 163 & 61 \\
B & $\mathrm{CO}_{2}$ & SW & 80 & 123 & 60 \\
A + B & $\mathrm{CO}_{2}$ & SW & 80 & 216 & 68 \\
\hline
\end{tabular}

Average bubble diameter of the foam can also provide an insight into the nature of the foam at a given time. Figure 4 shows the average bubble radius as a function of time for different foam systems generated using air in high salinity brine. The average bubble radius $\left(R_{a v g}\right)$ is calculated using Equation (4):

$$
R_{\text {avg }}=\frac{1}{n} \sum_{i=1}^{n} R_{i}
$$

where $n$ is a total number of bubbles and $R_{i}$ is the radius of a circle of the same area as the bubble area of the bubble is observed. On comparison of bubble size of surfactant-A and surfactant-B, initially, the average bubble size of surfactant-A (fluorinated zwitterionic) was higher compared to surfactant-B (hydrocarbon zwitterionic). However, in less than fifteen minutes, the average bubble size of the foam generated using surfactant-B exceeds the bubble size of the foam generated using surfactant-A. This clearly shows that the surfactant-B have higher foamability compared to the surfactant-A. However, the foam generated using the surfactant-A is more stable compared to the foam generated using surfactant-B. After five minutes, the increase in the average bubble size of surfactant- $B$ was much higher. After $1.5 \mathrm{~h}$, the average bubble size of the foam generated using surfactant-B was reached to $900 \mu \mathrm{m}$ and for surfactant-A, it was $500 \mu \mathrm{m}$. The increase in the bubble size indicates the decay in foam volume either due to coalescence or coarsening. Coalescence is the rupture of a liquid film that holds two neighboring bubbles, while the coarsening is the result of gas transfer from smaller to big bubbles leading to the disappearance of smaller bubbles [44]. The average bubble size of the foam generated using a mixture of surfactant- $\mathrm{A}$ and surfactant- $\mathrm{B}$ have the least bubble diameter for first fifty minutes. This indicates that the mixture of fluorinated and hydrocarbon zwitterionic surfactants significantly improve the foamability and stability compared to the hydrocarbon zwitterionic surfactant. The stability of the foam generated by the mixture surfactant is higher compared to hydrocarbon zwitterionic surfactant.

In summary, foam generation and foam stability can be enhanced using a mixture of zwitterionic fluorinated surfactant and zwitterionic hydrocarbon surfactant instead of using them individually. The synergetic action was observed when either air or $\mathrm{CO}_{2}$ was used as a gas medium. 


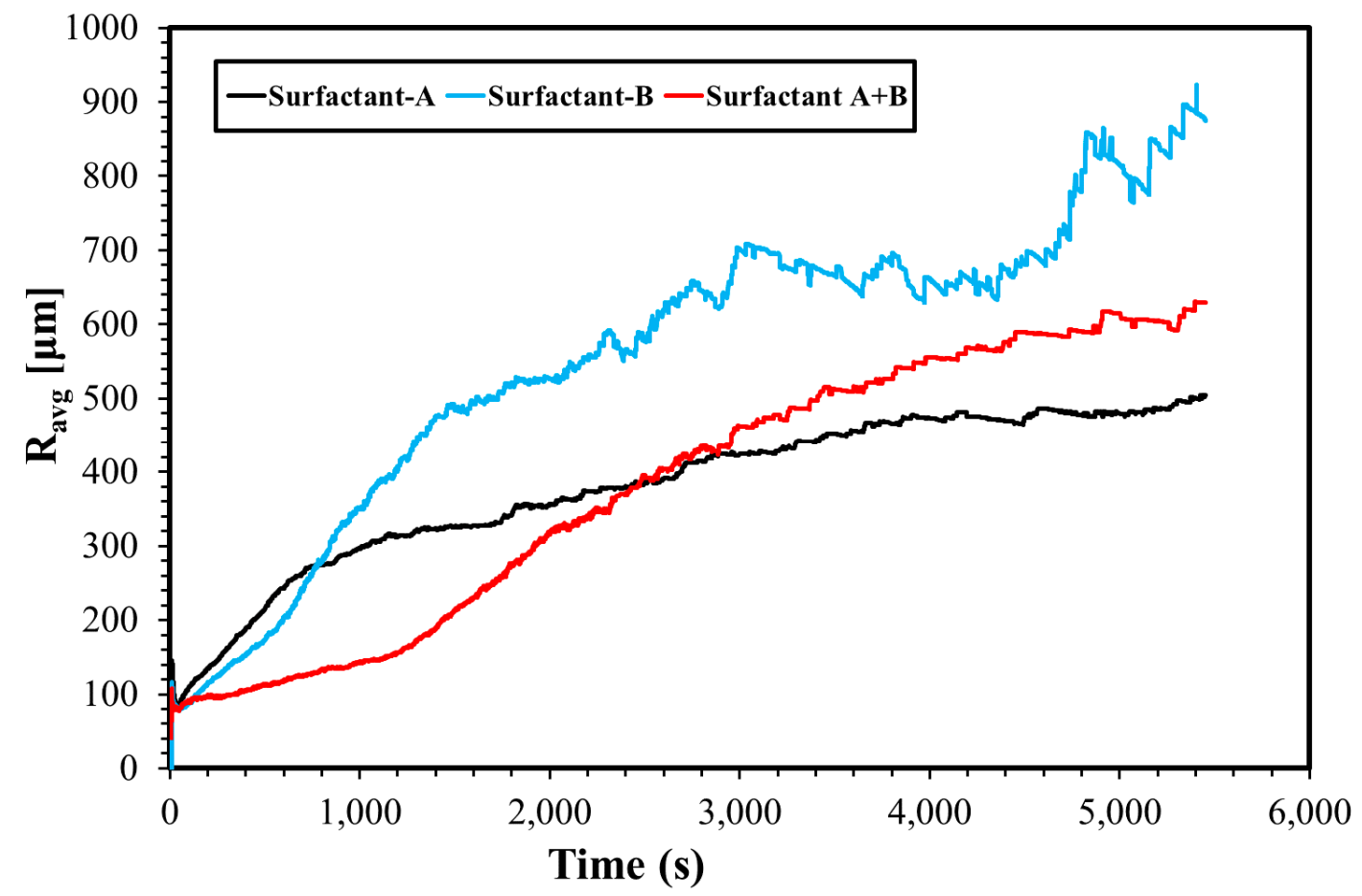

Figure 4. Bubble size of foam generated using different surfactant systems in high salinity brine using air injection at $25^{\circ} \mathrm{C}$.

Effect of salinity was also evaluated by comparing the foaming behavior of all surfactants in deionized water and synthetic seawater using $\mathrm{CO}_{2}$ as a gas medium. Figure 5 shows the comparison of foam volume generated in deionized and synthetic seawater. The foam volume generated using deionized water was lower compared to the foam volume generated using synthetic seawater. Addition of salts usually reduces the surface tension and critical micelle concentration of the surfactants [45]. Salinity increases surfactant adsorption at the air-water interface and reduces electrostatic double layer repulsion between the surfactants. Increased adsorption enables more surfactant molecules to trap air, thus increasing foamability [46,47]. The balance between these two forces determines the initial foam height [48]. Sun et al. observed that increasing the salinity of the system increased the foamability up to certain concentration. However, a further increase in the concentration reduced the foamability [45]. This was due to the precipitation of the ionic surfactant at a higher salt concentration which resulted in reduced foamability. However, in this case, all surfactants were soluble at investigated salinity and no precipitation was observed. Therefore, the foamability in the synthetic seawater increased compared the foamability in deionized water. Other literature also reports an optimum concentration of salinity for maximum foamability [49]. This also suggests that the compatibility of the surfactant at given condition should be assessed and only compatible surfactants should be used.

The FVS data of surfactants in deionized water is shown in Figure 6. Comparison of $t_{\mathrm{FV} 550}$ values for different surfactants in $\mathrm{CO}_{2}$ shows that the foam half-life time in the synthetic seawater is much higher compared to the foam-half time in deionized water for all surfactant. Also, it is evident that the surfactant-A has higher half-life time compared to surfactant- $\mathrm{B}$ in both synthetic seawater and deionized water. Though, the initial foam generated using surfactant- $\mathrm{A}$ was less compared the foam generated using surfactant- $\mathrm{B}$, the stability of the foam generated using surfactant-A was higher. The more interesting results were observed using a mixture of surfactant-A and surfactant-B. The half-life time of the mixture surfactant was higher compared to the half-life time of individual surfactants. The foamability of the mixture was also higher compared to the individual surfactants. This suggests that the synergetic action of hydrocarbon and fluorinated surfactant significantly improve the foaming properties in presence and absence of salts. 


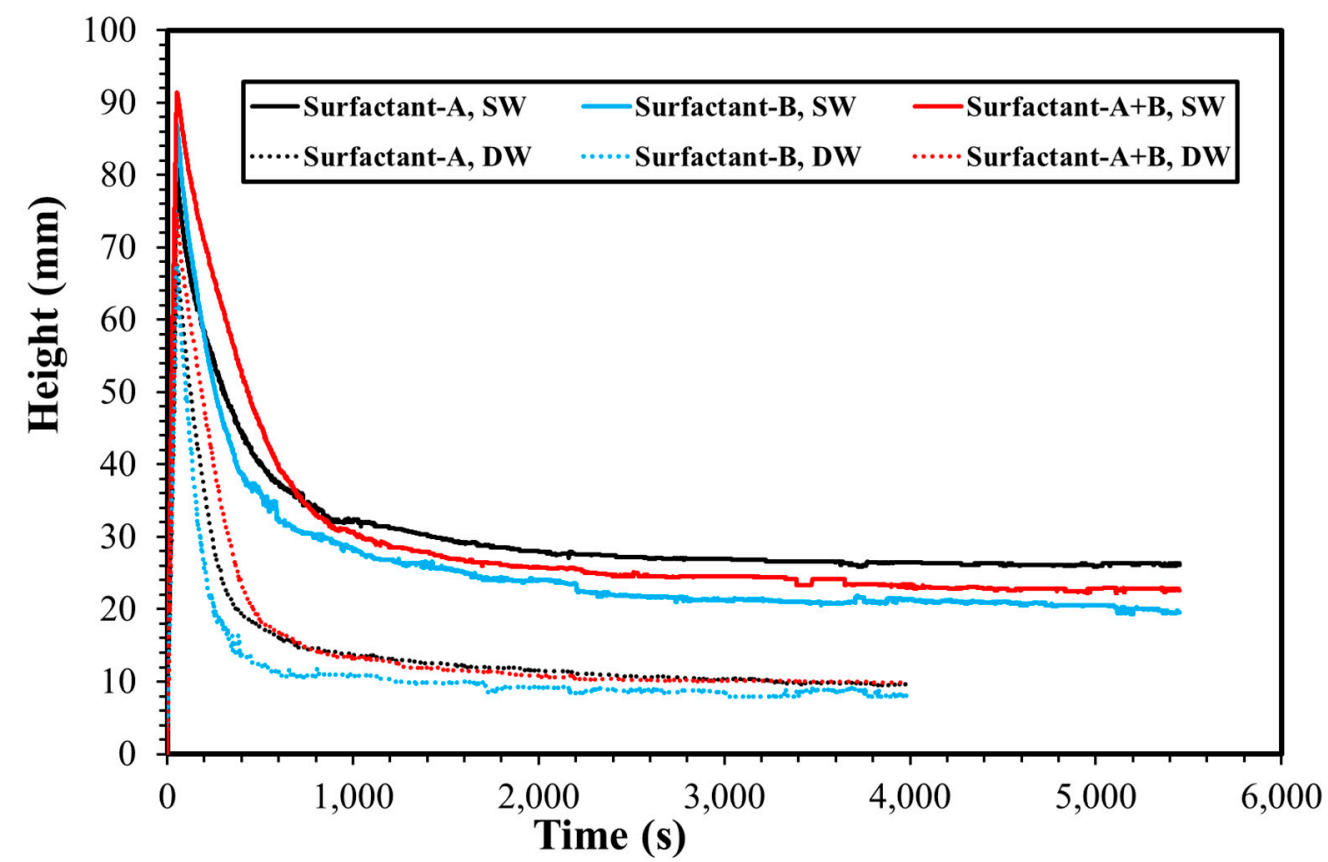

Figure 5. Foamability of different surfactant systems in seawater and deionized water using $\mathrm{CO}_{2}$ injection at $25^{\circ} \mathrm{C}$.

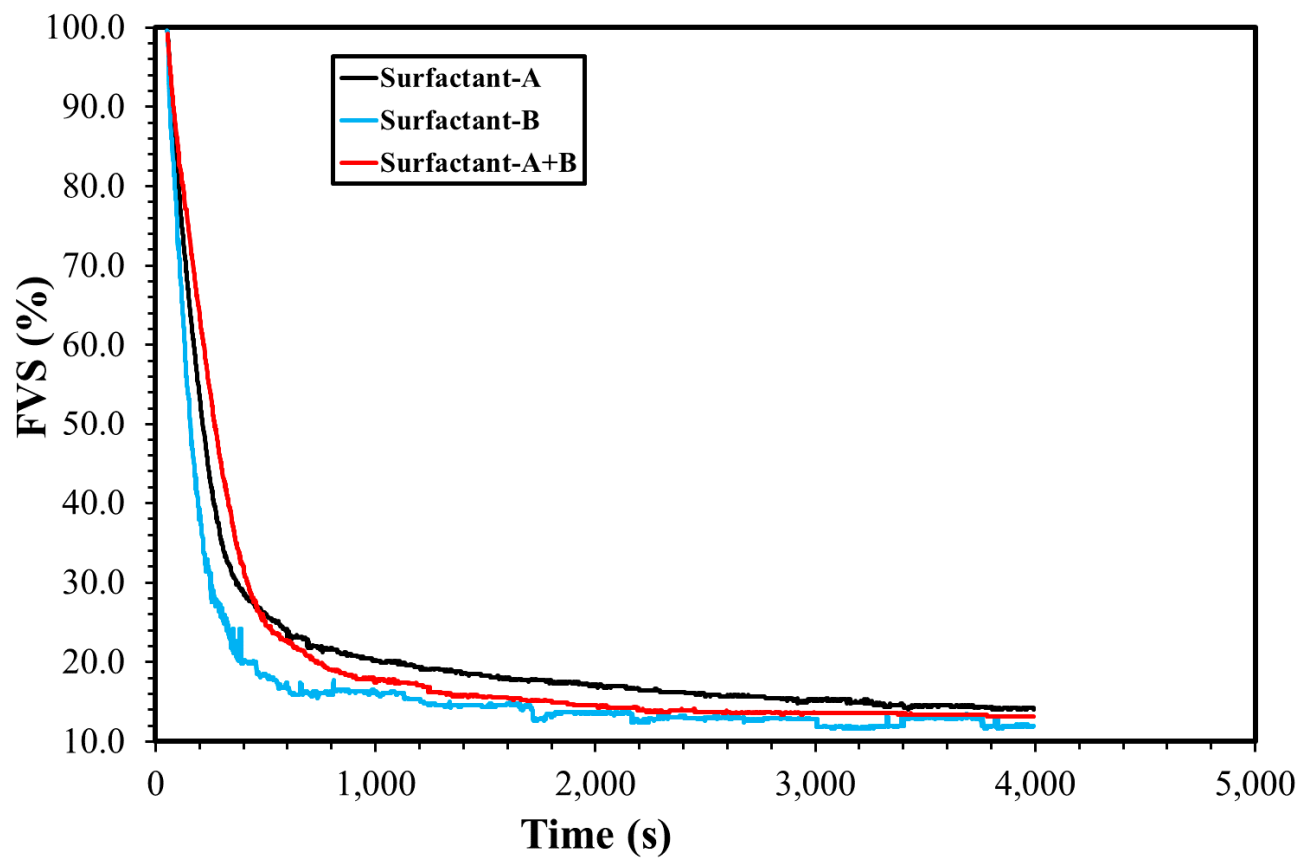

Figure 6. FVS of different surfactant systems in deionized water using $\mathrm{CO}_{2}$ injection at $25^{\circ} \mathrm{C}$.

For all investigated surfactants, the foamability and foam stability was also studied at high temperature $\left(80^{\circ} \mathrm{C}\right)$ using $\mathrm{CO}_{2}$ gas. Figure 7 shows the foam height of the foam using $\mathrm{CO}_{2}$ injection with fluorinated, hydrocarbon, and mixture surfactants at $80{ }^{\circ} \mathrm{C}$. At high temperature, similar behavior was noticed, and the mixture of surfactant showed the best performance compared to the individual surfactants. The maximum foam half-life time was observed for mixture surfactant followed by surfactant-A and surfactant-B. The foamability of all surfactants were higher (initial foam height $>140 \mathrm{~mm}$ ) at $80{ }^{\circ} \mathrm{C}$ compared to the foamability at low temperature (initial foam height $<90 \mathrm{~mm}$ ). The high foam generated at high temperature is associated with the Brownian motion. The kinematic velocity of the ions increased at high temperature which causes a more frequent 
collision which increased the quantity of foam generated [50]. Although the foamability increased at high temperature, the foam stability decreased at high temperature.

Figure 8 shows the FVS of surfactants at high temperature $\left(80^{\circ} \mathrm{C}\right)$ when surfactant was dissolved in seawater. The foam half-life time and drainage half-life time are lower at high temperature compared to the corresponding value at low temperature, for all surfactants (Table 2). The low foam stability at high temperature is associated with the surface viscosity which causes rapid liquid drainage [50]. In summary, the foamability of all the surfactants were high at high temperature compared the foamability at low temperature. However, the foam stability was higher at low temperatures for all surfactants. In addition, at both high and low temperatures, the foam stability of mixture of fluorinated and hydrocarbon surfactant is more compared to individual surfactants. Therefor, for EOR application, a combination of hydrocarbon and fluorinated surfactant is better compared to individual surfactant at high temperature.

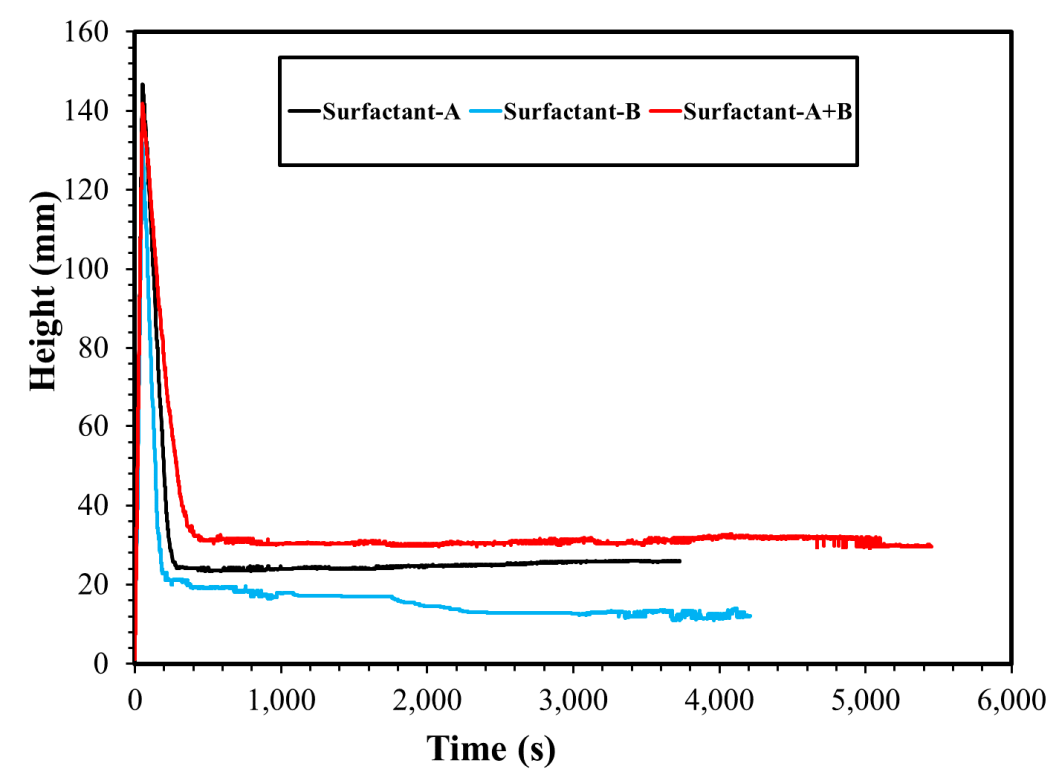

Figure 7. Foamability of different surfactant systems in seawater using $\mathrm{CO}_{2}$ injection at high temperature $\left(80^{\circ} \mathrm{C}\right)$.

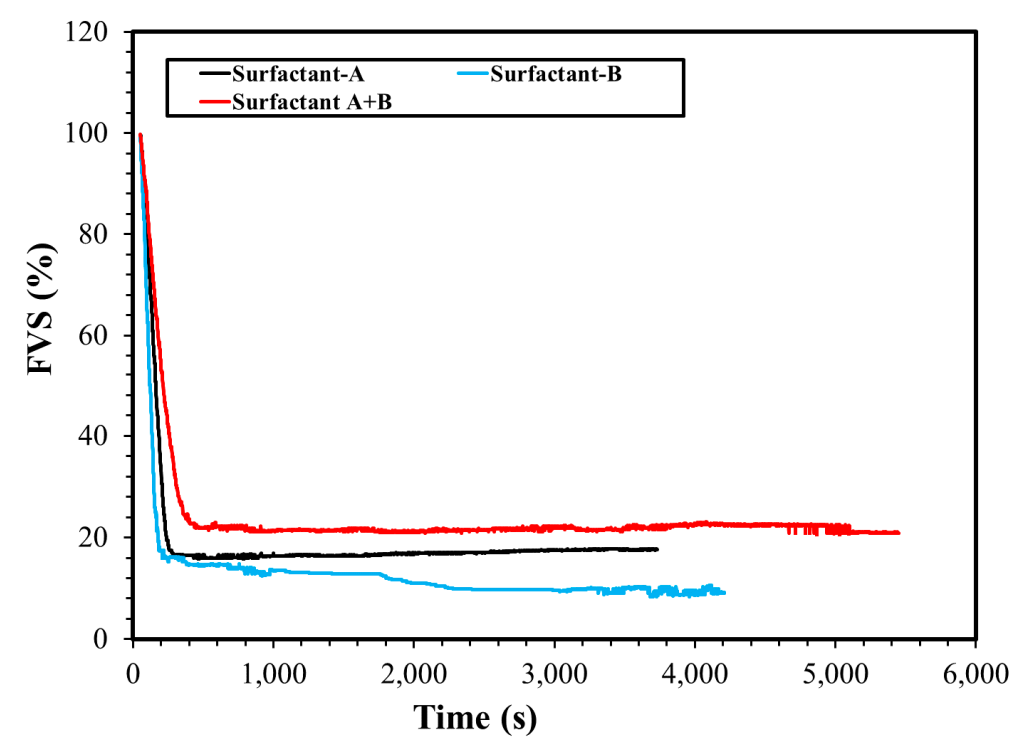

Figure 8. Foam volume stability (FVS) of surfactants using $\mathrm{CO}_{2}$ injection when dissolved in the $\mathrm{SW}$ at $80^{\circ} \mathrm{C}$. 


\section{Conclusions}

In this work the foaming properties of zwitterionic fluorinated and hydrocarbon surfactants were evaluated at different temperatures, salinity, and using two different gases $\left(\mathrm{CO}_{2}\right.$ and air). The following major conclusions were drawn:

(1) The foamability of the hydrocarbon surfactant was more compared to the fluorinated surfactant regardless of gas type, salinity, and temperature.

(2) The foam generated using fluorinated surfactant is more stable compared to the hydrocarbon surfactant.

(3) The mixture of hydrocarbon and zwitterionic surfactant could have improved foamability and foam stability compared to the individual surfactants.

(4) The foamability and foam stability was higher when the air was used as a gas medium.

(5) The foamability of all surfactants increased at high temperature due to Brownian motion in the liquid and enhanced kinematic viscosity leads to better foam generation. However, the foam stability reduced at high temperature.

(6) In the synthetic seawater, the foamability and foam stability of all investigated surfactants were higher compared to deionized water.

Author Contributions: The sole author M.S.K. designed, planned, and conducted experiments in addition to the write-up.

Funding: This research was funded by to Center for Integrative Petroleum Research, King Fahd University of Petroleum \& Minerals, grant number SF 17005.

Acknowledgments: I am thankful to Lionel Talley Fogang for conducting some of the experiments.

Conflicts of Interest: The author declares no conflict of interest.

\section{References}

1. Farajzadeh, R.; Muruganathan, R.; Rossen, W.; Krastev, R. Effect of gas type on foam film permeability and its implications for foam flow in porous media. Adv. Colloid Interface Sci. 2011, 168, 71-78. [CrossRef]

2. Gu, M.; Mohanty, K. Rheology of polymer-free foam fracturing fluids. J. Pet. Sci. Eng. 2015, 134, 87-96. [CrossRef]

3. Saxena, A.; Pathak, A.; Ojha, K. Synergistic effects of ionic characteristics of surfactants on aqueous foam stability, gel strength, and rheology in the presence of neutral polymer. Ind. Eng. Chem. Res. 2014, 53, 19184-19191. [CrossRef]

4. Ahmed, S.; Elraies, K.A.; Hashmet, M.R.; Alnarabiji, M.S. Empirical Modeling of the Viscosity of Supercritical Carbon Dioxide Foam Fracturing Fluid under Different Downhole Conditions. Energies 2018, 11, 782. [CrossRef]

5. Ahmed, S.; Elraies, K.A.; Hanamertani, A.S.; Hashmet, M.R. Viscosity models for polymer free $\mathrm{CO}_{2}$ foam fracturing fluid with the effect of surfactant concentration, salinity and shear rate. Energies 2017, 10, 1970. [CrossRef]

6. Lu, T.; Li, Z.; Zhou, Y. Flow Behavior and Displacement Mechanisms of Nanoparticle Stabilized Foam Flooding for Enhanced Heavy Oil Recovery. Energies 2017, 10, 560. [CrossRef]

7. Núñez-López, V.; Gil-Egui, R.; Hosseini, S.A. Environmental and Operational Performance of $\mathrm{CO}_{2}-\mathrm{EOR}$ as a CCUS Technology: A Cranfield Example with Dynamic LCA Considerations. Energies 2019, 12, 448. [CrossRef]

8. Wang, Q.; Yang, S.; Han, H.; Wang, L.; Qian, K.; Pang, J. Experimental Investigation on the Effects of $\mathrm{CO}_{2}$ Displacement Methods on Petrophysical Property Changes of Ultra-Low Permeability Sandstone Reservoirs Near Injection Wells. Energies 2019, 12, 327. [CrossRef]

9. Qian, K.; Yang, S.; Dou, H.; Wang, Q.; Wang, L.; Huang, Y. Experimental investigation on microscopic residual oil distribution during $\mathrm{CO}_{2}$ Huff-and-Puff process in tight oil reservoirs. Energies 2018, 11, 2843. [CrossRef] 
10. Hanamertani, A.S.; Pilus, R.M.; Manan, N.A.; Mutalib, M.I.A. The use of ionic liquids as additive to stabilize surfactant foam for mobility control application. J. Pet. Sci. Eng. 2018, 167, 192-201. [CrossRef]

11. Farajzadeh, R.; Andrianov, A.; Zitha, P. Investigation of immiscible and miscible foam for enhancing oil recovery. Ind. Eng. Chem. Res. 2009, 49, 1910-1919. [CrossRef]

12. Sakai, T.; Kaneko, Y. The effect of some foam boosters on the foamability and foam stability of anionic systems. J. Surfactants Deterg. 2004, 7, 291-295. [CrossRef]

13. Sun, L.; Bai, B.; Wei, B.; Pu, W.; Wei, P.; Li, D.; Zhang, C. Recent advances of surfactant-stabilized $\mathrm{N}_{2} / \mathrm{CO}_{2}$ foams in enhanced oil recovery. Fuel 2019, 241, 83-93. [CrossRef]

14. Osei-Bonsu, K.; Shokri, N.; Grassia, P. Foam stability in the presence and absence of hydrocarbons: From bubble-to bulk-scale. Colloids Surf. A Physicochem. Eng. Asp. 2015, 481, 514-526. [CrossRef]

15. Verma, A.; Chauhan, G.; Ojha, K. Characterization of $\alpha$-olefin sulfonate foam in presence of cosurfactants: Stability, foamability and drainage kinetic study. J. Mol. Liq. 2018, 264, 458-469. [CrossRef]

16. Telmadarreie, A. Static and Dynamic Performance of Wet Foam and Polymer-Enhanced Foam in the Presence of Heavy Oil. Colloids Interfaces 2018, 2, 38. [CrossRef]

17. Bal, D.K.; Patra, S.; Ganguly, S. Effectiveness of foam-gel formulation in homogenizing the $\mathrm{CO}_{2}$ front during subsurface sequestration. J. Nat. Gas Sci. Eng. 2015, 27, 994-1004. [CrossRef]

18. Zeng, Y.; Ma, K.; Farajzadeh, R.; Puerto, M.; Biswal, S.L.; Hirasaki, G.J. Effect of Surfactant Partitioning Between Gaseous Phase and Aqueous Phase on $\mathrm{CO}_{2}$ Foam Transport for Enhanced Oil Recovery. Transp. Porous Media 2016, 114, 777-793. [CrossRef]

19. Xue, Z.; Worthen, A.J.; Da, C.; Qajar, A.; Ketchum, I.R.; Alzobaidi, S.; Huh, C.; Prodanović, M.A.; Johnston, K.P. Ultradry carbon dioxide-in-water foams with viscoelastic aqueous phases. Langmuir 2015, 32, $28-37$. [CrossRef] [PubMed]

20. Chukwudeme, E.A.; Hamouda, A.A. Enhanced oil recovery (EOR) by miscible $\mathrm{CO}_{2}$ and water flooding of asphaltenic and non-asphaltenic oils. Energies 2009, 2, 714-737. [CrossRef]

21. Tang, S.; Zheng, Y.; Yang, W.; Wang, J.; Fan, Y.; Lu, J. Experimental Study of Sulfonate Gemini Surfactants as Thickeners for Clean Fracturing Fluids. Energies 2018, 11, 3182. [CrossRef]

22. Nazari, N.; Tsau, J.-S.; Barati, R. $\mathrm{CO}_{2}$ foam stability improvement using polyelectrolyte complex nanoparticles prepared in produced water. Energies 2017, 10, 516. [CrossRef]

23. He, H.; Fu, J.; Hou, B.; Yuan, F.; Guo, L.; Li, Z.; You, Q. Investigation of Injection Strategy of Branched-Preformed Particle Gel/Polymer/Surfactant for Enhanced Oil Recovery after Polymer Flooding in Heterogeneous Reservoirs. Energies 2018, 11, 1950. [CrossRef]

24. Azad, M.S.; Sultan, A.S.; Nuaim, S.A.; Mahmoud, M.; Hussein, I.W. Could VES be a part of Hybrid option to recover Heavy oil in Complex Heavy oil Reservoirs. In Proceedings of the SPE Heavy Oil Conference-Canada, Calgary, AB, Canada, 10-12 June 2014.

25. Mahmoud, M.A.; Hussein, I.A.; Sahib, M.; Sultan, A.S. Rheological Assessment of VES as an EOR Fluid in Carbonate Reservoir. In Proceedings of the SPE EOR Conference at Oil and Gas West Asia, Muscat, Oman, 31 March-2 April 2014.

26. Kamal, M.S.; Shakil Hussain, S.M.; Fogang, L.T. A Zwitterionic Surfactant Bearing Unsaturated Tail for Enhanced Oil Recovery in High-Temperature High-Salinity Reservoirs. J. Surfactants Deterg. 2018, 21, 165-174. [CrossRef]

27. Hussain, S.S.; Kamal, M.S.; Fogang, L.T. Effect of internal olefin on the properties of betaine-type zwitterionic surfactants for enhanced oil recovery. J. Mol. Liq. 2018, 266, 43-50. [CrossRef]

28. Hussain, S.S.; Animashaun, M.A.; Kamal, M.S.; Ullah, N.; Hussein, I.A.; Sultan, A.S. Synthesis, Characterization and Surface Properties of Amidosulfobetaine Surfactants Bearing Odd-Number Hydrophobic Tail. J. Surfactants Deterg. 2016, 19, 413-420. [CrossRef]

29. Kamal, M.S.; Hussain, S.S.; Sultan, A.S. Development of Novel Amidosulfobetaine Surfactant-Polymer Systems for EOR Applications. J. Surfactants Deterg. 2016, 19, 989-997. [CrossRef]

30. Kamal, M.S. A Review of Gemini Surfactants: Potential Application in Enhanced Oil Recovery. J. Surfactants Deterg. 2016, 19, 1-14. [CrossRef]

31. Mukerjee, P. Salt effects on nonionic association colloids. J. Phys. Chem. 1965, 69, 4038-4040. [CrossRef]

32. Adkins, S.S.; Chen, X.; Chan, I.; Torino, E.; Nguyen, Q.P.; Sanders, A.W.; Johnston, K.P. Morphology and stability of $\mathrm{CO}_{2}$-in-water foams with nonionic hydrocarbon surfactants. Langmuir 2010, 26, 5335-5348. [CrossRef] 
33. Puerto, M.; Hirasaki, G.J.; Miller, C.A.; Barnes, J.R. Surfactant systems for EOR in high-temperature, high-salinity environments. SPE J. 2012, 17, 11-19. [CrossRef]

34. Da, C.; Alzobaidi, S.; Jian, G.; Zhang, L.; Biswal, S.L.; Hirasaki, G.J.; Johnston, K.P. Carbon dioxide/water foams stabilized with a zwitterionic surfactant at temperatures up to $150{ }^{\circ} \mathrm{C}$ in high salinity brine. J. Pet. Sci. Eng. 2018, 166, 880-890. [CrossRef]

35. Effendy, I.; Maibach, H.I. Surfactants and experimental irritant contact dermatitis. Contact Dermat. 1995, 33, 217-225. [CrossRef]

36. Kamal, M.S.; Sultan, A.; Hussein, I.; Hussain, S.; AlSofi, A.M. Screening of Surfactants and Polymers for High Temperature High Salinity Carbonate Reservoirs. In Proceedings of the SPE Kingdom of Saudi Arabia Annual Technical Symposium and Exhibition, Dammam, Saudi Arabia, 23-26 April 2018.

37. Al-Amodi, A.O.; Al-Mubaiyedh, U.A.; Sultan, A.S.; Kamal, M.S.; Hussein, I.A. Novel fluorinated surfactants for enhanced oil recovery in carbonate reservoirs. Can. J. Chem. Eng. 2016, 94, 454-460. [CrossRef]

38. Kamal, M.S.; Sultan, A.S.; Al-Mubaiyedh, U.A.; Hussein, I.A.; Feng, Y. Rheological Properties of Thermoviscosifying Polymers in High-temperature and High-salinity Environments. Can. J. Chem. Eng. 2015, 93, 1194-1200. [CrossRef]

39. Kamal, M.S.; Adebayo, A.R.; Fogang, L.T.; Barri, A. Improving Gas Sequestration by Surfactant-Alternating-Gas Injection: A Comparative Evaluation of Surfactant Type and Concentration. J. Surfactants Deterg. 2018, 21, 667-675. [CrossRef]

40. Wang, Y.; Zhang, Y.; Liu, Y.; Zhang, L.; Ren, S.; Lu, J.; Wang, X.; Fan, N. The stability study of $\mathrm{CO}_{2}$ foams at high pressure and high temperature. J. Pet. Sci. Eng. 2017, 154, 234-243. [CrossRef]

41. Princen, H.; Mason, S. The permeability of soap films to gases. J. Colloid Sci. 1965, 20, 353-375. [CrossRef]

42. Sun, R.; Hu, W.; Duan, Z. Prediction of nitrogen solubility in pure water and aqueous $\mathrm{NaCl}$ solutions up to high temperature, pressure, and ionic strength. J. Solut. Chem. 2001, 30, 561-573. [CrossRef]

43. Zhao, H.; Fedkin, M.V.; Dilmore, R.M.; Lvov, S.N. Carbon dioxide solubility in aqueous solutions of sodium chloride at geological conditions: Experimental results at 323.15, 373.15, and $423.15 \mathrm{~K}$ and $150 \mathrm{bar}$ and modeling up to $573.15 \mathrm{~K}$ and 2000bar. Geochim. Cosmochim. Acta 2015, 149, 165-189. [CrossRef]

44. Wang, C.; Fang, H.; Gong, Q.; Xu, Z.; Liu, Z.; Zhang, L.; Zhang, L.; Zhao, S. Roles of catanionic surfactant mixtures on the stability of foams in the presence of oil. Energy Fuels 2016, 30, 6355-6364. [CrossRef]

45. Sun, J.; Jing, J.; Brauner, N.; Han, L.; Ullmann, A. An oil-tolerant and salt-resistant aqueous foam system for heavy oil transportation. J. Ind. Eng. Chem. 2018, 68, 99-108. [CrossRef]

46. Behera, M.R.; Varade, S.R.; Ghosh, P.; Paul, P.; Negi, A.S. Foaming in micellar solutions: Effects of surfactant, salt, and oil concentrations. Ind. Eng. Chem. Res. 2014, 53, 18497-18507. [CrossRef]

47. Varade, S.R.; Ghosh, P. Foaming in aqueous solutions of zwitterionic surfactant: Effects of oil and salts. J. Dispers. Sci. Technol. 2017, 38, 1770-1784. [CrossRef]

48. Wang, J.; Nguyen, A.V.; Farrokhpay, S. A critical review of the growth, drainage and collapse of foams. Adv. Colloid Interface Sci. 2016, 228, 55-70. [CrossRef]

49. Kumar, S.; Mandal, A. Investigation on stabilization of $\mathrm{CO}_{2}$ foam by ionic and nonionic surfactants in presence of different additives for application in enhanced oil recovery. Appl. Surf. Sci. 2017, 420, 9-20. [CrossRef]

50. Wang, H.; Guo, W.; Zheng, C.; Wang, D.; Zhan, H. Effect of temperature on foaming ability and foam stability of typical surfactants used for foaming agent. J. Surfactants Deterg. 2017, 20, 615-622. [CrossRef]

(C) 2019 by the author. Licensee MDPI, Basel, Switzerland. This article is an open access article distributed under the terms and conditions of the Creative Commons Attribution (CC BY) license (http://creativecommons.org/licenses/by/4.0/). 